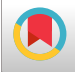

\title{
Experience of Depression Among Female Students Residing in a Dormitory Complex: A Qualitative Study
}

\author{
Abdolrasool Hasanifar ${ }^{1,{ }^{*}}$ and Behrouz Roustakhiz ${ }^{2}$ \\ ${ }^{1}$ Department of Social Sciences, University of Sistan and Baluchestan, Zahedan, Iran \\ ${ }^{2}$ Department of Anthropology, Faculty of Social Sciences, University of Tehran, Tehran, Iran \\ "Corresponding author: Department of Social Sciences, University of Sistan and Baluchestan, Zahedan, Iran, Tel: +98-9127100614, Email: hasanifar@lihu.usb.ac.ir
}

Received 2018 August 17; Revised 2019 June 12; Accepted 2019 December 20.

\begin{abstract}
Background: Depression is one of the most common issues among mental health related issues amongst Iranian students; a topic that has thus far been the area of research by lots of researchers with the medical and psychological origins. These researches are mainly conducted using a quantitative approach.

Objectives: The main purpose of this study was to achieve qualitative understanding of depression experience and the representational implications of this phenomenon among those depressed. In this study, the question is how individuals experience and perceive depression.

Methods: This is a qualitative study with directed approach to content analysis of in-depth semi-structured interviews. Therefore, the findings were obtained through interviews with 15 female students and analyzed using the thematic analysis technique.

Results: The collected narratives represent depression as an unpleasant experience with damaging consequences for body, soul, and social relationships. However, after reflecting on these narratives, it was found out that depression is a process and not an immediate occurrence; this process was followed using the following six main categories or themes that have been derived from interviews: (1) underlying family conditions; (2) underlying education and university conditions; (3) underlying dormitory and environmental conditions; (4) fear of the future and imagining a tomorrow full of darkness; (5) cyberspace, experience of depression and feeling of isolation; and (6) failed emotional attachment, experience of depression, and feelings of grief. According to the findings, the "situation in jeopardy" seems to be the best concept through which "experience of depression" can be brought to an anthropological understanding.

Conclusions: Therefore, discussions have been made on the need to form a framework for broader support networks and the rethinking of socio-cultural and economic policies at the meso and macro levels of the society. It seems that the present research also implicitly opens a way to explore and understand the inter-subjectivity of students as an important part of Iranian society.
\end{abstract}

Keywords: Experience of Depression, Mental Health, Phenomenology, Iranian Inter-Subjectivity, Situation in Jeopardy

\section{Background}

Depression is presently one of the most widespread phenomena faced by people and, in fact, human societies (1). Despite the large social dimensions and implications that can be considered for depression, this phenomenon and many similar cases are considered to be more of a damaging state or mental diseases, which should be treated on time. Being successful or unsuccessful, the medical and psychology sciences will soon be involved with the problem from this perspective. Presently, social sciences, in general, and anthropology, in particular, will find common grounds, in a fundamental desire, with these sciences, particularly psychology; the fact which is how individuals experience and perceive these mental states. However, understanding of the problem faced by the individual re- quires understanding of the particular social contexts in which he or she will be. The present research, moving from this perspective, aimed to investigate the depression experience among female students residing in a dormitory complex using a qualitative approach. The emphasis on qualitative study is that it gives us the opportunity to go beyond number (statistical tests), and provide conditions for a deeper understanding of the diverse and unique experiences. The choice of female students for study has been due to the necessity that they are prone to depression more than others, because of their gender and their position in society. Also, the choice of "university" and "students" as a case to be studied, however, goes back to the fact that depression is one of the most common issues among mental health issues amongst university students (2-10); presently, 
dormitory atmosphere, especially for newcomer students, leads to experiences that may cause troubles and problems for them $(11,12)$. This discussion is made on students as a group, which when given the demographic structure and social status of Iran, will manage the future of this country; hence, there is a direct and inseparable relationship between their body and, more importantly, the mental health and the health status at the national level.

As discussed earlier, specifically, with regard to the issue of depression among the studied students, the main questions focused on by this research are: How the individual or participant student defines and actually perceives the depression? Does she regard herself as depressed person? What kinds of experience occurred to his/her minds that are assumed to be involved in his/her depression? These experiences connect him/her to what spaces, times, places, persons, and periods? Where does the accepted and perceived depression direct the personal life routine and his/her social life? What are the representational implications of this experience? As suggested by these questions, in contrast to the existing empirical background, the aim this study is not to investigate the level of depression among students using quantitative method, but the important goal is to discuss about a human experience in the social context and to achieve an understanding about its implications.

\section{Methods}

\subsection{Field and Setting of the Study}

The field of this study is a dormitory complex in the city of Zahedan, where female students studying in a state university live; in addition, it was also possible for the researchers to accompany the students in the university campus. Researchers and authors have also had a history of studying and teaching in the aforementioned university space and this lived experience or a close encounter plays a significant role in understanding the subject. Zahedan is a city in the most southeastern province of Iran; this region is still in the lowest ranks in terms of many human and economic development indicators due to its slow growth rate (13). As regards the native selection policy of the Iranian universities, individuals from the provinces of Sistan and Baluchestan, Kerman, Hormozgan and South Khorasan make up most students of the studied university and its dormitory complex. Accordingly, the participants of the study include a combination of female students from different cities have come to the dormitory complex in $\mathrm{Za}$ hedan. Specifically, from 15 interviewees, eight of them were from Sistan and Baluchestan, four from Kerman, two from Hormozgan, and one from South Khorasan. Profile of participants is provided in the following table, but due to ethical consideration, the more details have been avoided (Table 1).

\subsection{Design, Participants, and Analysis}

This research, based on its nature and objectives, uses a kind of qualitative methodology among available methodological approaches (14). Since the aim this study is to understand the participants' experiences on the depression phenomenon and related issues, we have used qualitative content analysis. In this type of approaches, the researchers aim to present a contextual and structural description on "nature" and "how" of a phenomenon experienced by the subjects (15). The findings were obtained through semi-structured but deep interviews with people who volunteered to participate in the present research and believed they felt some degree of depression. The dialogue was advanced with the participants who were purposefully selected during the non-probability sampling on the main questions: What have happened to you during the experience of this depression and even before it? What contexts or conditions are effective on the formation of this phenomenon in your point of view? A total of 15 students within the age range of 19 to 22 years old participated in the study, most of who were studying in the humanities. Reliance on these was due to achievement of theoretical saturation in data; this means that, no new data was received after the interview with this number. The interviews were held in the first semester of the academic year of 2017 - 2018. "Thematic analysis" technique was used to analyze the findings (16); in other words, important sentences or quotations containing key points about nature and how of the experience of depression were highlighted and presented following the selected themes. Specifically, the data analysis steps in this study were: (1) implementation of interviews; (2) reading text and notes of ideas or semantic associations; (3) highlighting important sentences or quotes and extracts into sub-themes; (4) classification of sub-themes and presentation within the main categories; and (5) summing up the discussion below is a core category.

\subsection{Ethical Considerations}

Most of the interviews and talks with the participants, while considering all the specific ethical constraints and considerations that exist in the study setting, were performed by trained researchers whose gender was similar to that of the participants and were "roommates" in some cases that seem effective in obtaining more valid and reliable findings. The adherence to the research ethics requires paying respect to the principle of "anonymity" and "confidentiality" as much as possible. Thus, the name of university and the dormitory complex was not mentioned 


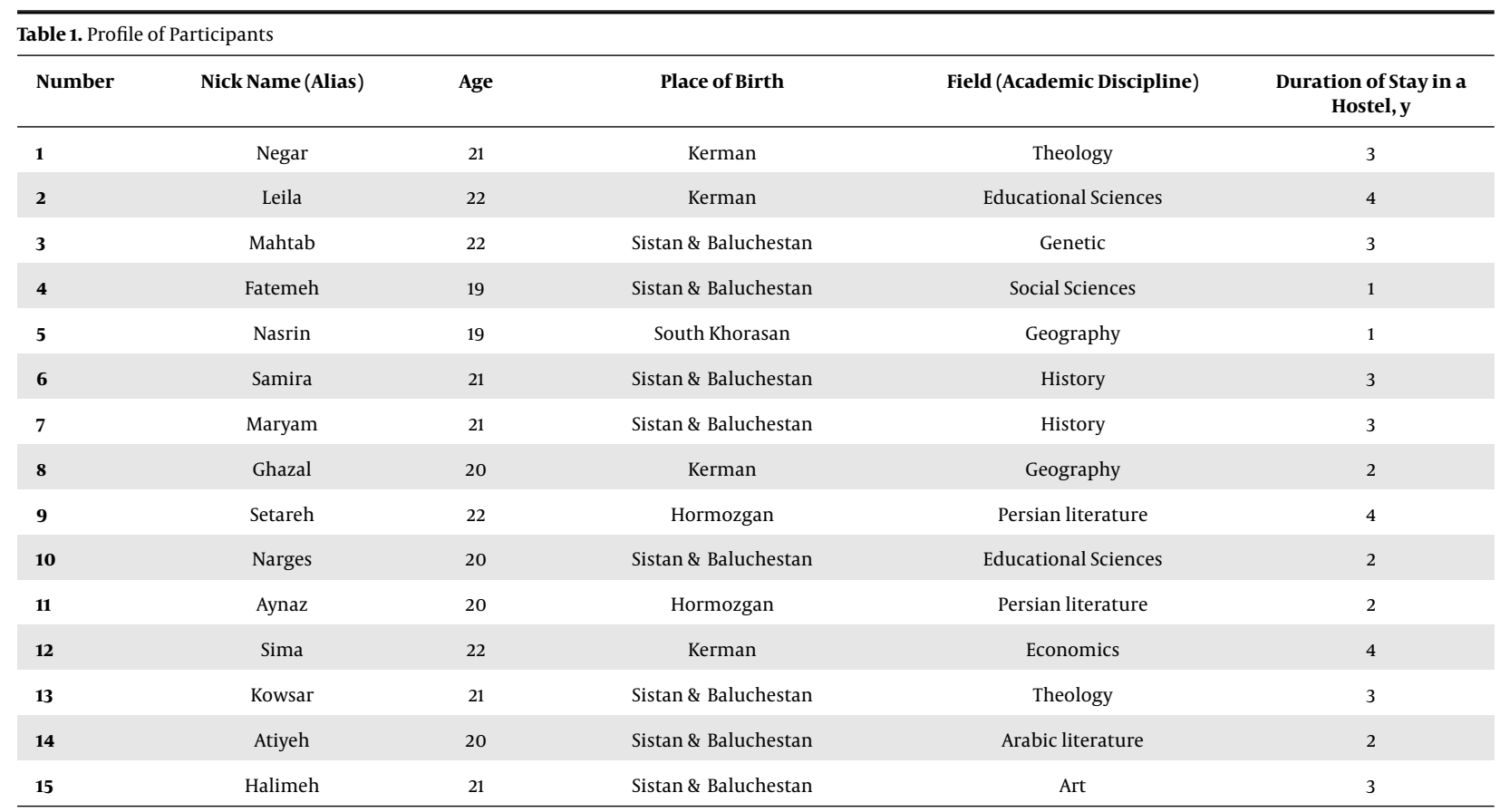

and attempts were made to avoid mentioning any sign also. In addition, since the student's information, including name, last name, dormitory name or room number, field of study, etc., were not mentioned. The names used subsequently are completely "alias" and are not their real names. Also, participants were free to participate in the interview and cooperate with the researchers.

\subsection{Credibility and Confirmability}

In order to obtain valid findings and analyses, various strategies were considered. First, attempts were made to select the best method for the study. Since the aim of the present study was to achieve an understanding of nature and how of the experience of depression and its implications, the best method was identified as qualitative content analysis. Second, attempts were made to select appropriate samples for the research. As a result of this, attempts were made to attract the participation of those whose appearance represents their inner turmoil. These individuals had a lot to say and wanted their voice to be heard. Third, the talks were made in details in such a way that a kind of "saturation" was achieved. Fourth, the talks and observations were recorded and implemented with maximum accuracy. Obviously, the simultaneous use of interviews and observation technique and different interviewers was to reach a "triangulation" (17). The emphasis on observation -along with the interview, as the main technique in collecting data-in this study was in order to communicate closely with the issue and achieving a better understanding of the participants' conditions. Finally, "peer review or debriefing" and "member checking" were used during analysis and interpretation of findings (18); in a way that the results and inferences were evaluated by a number of academic experts and also, were raised in the student settings and the students' own evaluation of the raised cases was also considered. However, one cannot make any claim regarding raising absolute and generalizable propositions or summaries regardless of theoretical and insight orientations in such research and also such claim was not made.

\section{Results}

The talks and interviews performed showed that all student participants reveal unpleasant feelings that lead to states of "bad temper", "isolation", "lack of sleep" and "over-sleeping", etc., as symptoms of their depression. While expressing the these feelings and states of mind, most of the subjects referred to self-damaging experiences and narrate cases such as "irregular pill use", "self-injury" and "suicide attempts". Some consequences of depression among these students are subsequently stated; but here, it is necessary to refer to the aforementioned narratives to achieve an understating of what they have experienced. While referring to her first days of attendance in the university, one student says:

"I was depressed during the very first weeks I came, I was just crying, it was too difficult for me such that I wanted to commit suicide, but it was a failed attempt. I always use pills, I lost $11 \mathrm{~kg}$. One or two weeks passed. I was 
so thin or skinny. I always feel bad in the dormitory as if a heavy truck has fallen on me. I stared at a point and kept silent. I was always thinking and wanted God to kill me. I felt so bad" (Negar, 21 years old).

While expressing herself, she feels unmotivated and shows no goal for herself; another student narrates similar unpleasant experiences:

"I always have feelings of being unmotivated and aimless. I have to take pills. Sometimes I cry from the bottom of my heart for one minute and slam my head against the door and wall. My self-confidence is too low. I underestimate myself. I sometimes beat myself, pull my hair and tear my notebooks" (Leila, 22 years old).

While reviewing all these narratives, the fundamental question remains: What is the source and origin of this elevated level of sorrowful frustration; an open question raised from each of the participants and allowed to travel to the many near and far places. They were accompanied in this trip (Table 2).

\subsection{Underlying Family Conditions}

The experiences of the participants show that the family conditions should be considered as the context causing many of the current turmoil and problems for them. The family, in their point of view, must basically be a peaceful and encouraging place. It is as if everything has conspired to put the house in chaos. The discussion is on the formation of an anxiety that has penetrated into the body, soul and mind of some of the participants of the present research. The key issues that have been raised following this topic mainly focused on the following cases: inconsistency and conflict in the family; continuous verbal and physical violence in the family; lack of affection in the family; family financial and economic problems; and compulsory unwanted marriage by the family.

"I have a thyroid problem; I have a severe nervous disorder; which is due to emotional deficiencies caused by my dad. My parents had very bad relationship with each other. I saw how my dad beats my mom, since I was a child. We were under pressure economically, too. My mom could no longer tolerate it. After a while, she also suffered from a nervous problem and had to be supervised by a doctor. My dad was very violent [...] I am the eldest daughter of the family and tried to give my mom a hand in the absence of my dad and help her. I was under lots of pressure because my dad left me and my mom in the hospital and went away for a while. I was hit (emotionally) a lot. And then enter the university with this spirit, and compared myself with others. And these made me feel bad" (Leila, 22 years old).

It is considered a simplification to limit the problem faced by Leila and many other students with similar conditions to their home and family framework. Their home and family is the product of the social context and the special culture in which "inequality" seems to be internalized. In fact, the narratives of all the participants show that they are at the lowest level of social and economic welfare.

"My dad is retired but he pays lots of installment and debt. Of two million-odd Tomans that my father earns monthly, (almost) all of it is spent on our installments and that's why my dad has to go to work after 10 years of retirement. There is no son in our family who can work and make money. We are two daughters and both of us are students with our own student expenditures. I myself is looking for job, but since I am a girl no one employed me. My expenditures are high, now I have to pay 500,000 Tomans until the next week (to university)" (Mahtab, 22 years old).

The macro-level structural inequality extends at the meso and micro level throughout the society. The evidence of such extension is the involvement of the studied female students in a subaltern position; subaltern in a family that is based on a strongly patriarchal structure.

"My mental pain is due to my family problems. I'm supposed to marry somebody whom I certainly don't love. I have no courage to say this; I mean I can't stay against my family at all. When I came here (university), my roommates are minding their own business. I can't talk with anybody. I feel lonely. This thought occurs to me in such situation and bothers me. I start crying and there is nobody who I can open up to" (Fatemeh, 19 years old).

\subsection{Underlying University and Education Conditions}

Some talks with the observations show that some of the participants made all their attempts to enter the university; sometimes with no mental image of what will happen after this entry; as if the university is perceived as the safe place where liberation occurs. The current mental image of the university is based on a prejudgment distinction; the distinction between an enclosed space and full of binding constraints, that is, the school and the space where the past constraints no longer exist, that is university. The past perception shows an image in which more facilitated conditions and more flexible context are seen; a perception that will be, however, broken and opens up a vague and dark picture before their eyes. We are discussing a distressing challenge that involves the students in a new "hazardous situation". The following is one of the most interesting and readable narrative on this issue:

"I thought that the university conditions are much easier; I mean I felt that the pressure we had at school, is not here; but all my mental images changed during the very first sessions we came to the classes. Every professor came and said that the university is not like the school; here, you should study harder and attend classes regularly, do practical work and the likes. I felt the fear in my heart during the very first days. I was very sacred and I'm still scared that 


\begin{tabular}{|c|c|c|c|}
\hline $\begin{array}{l}\text { The Phenomenon } \\
\text { Under Study }\end{array}$ & Core Category & Themes & Sub-Themes \\
\hline \multirow{22}{*}{$\begin{array}{l}\text { Experience of } \\
\text { Depression }\end{array}$} & \multirow{22}{*}{ Situation in jeopardy } & \multirow{5}{*}{ Underlying family condition } & Inconsistency and conflict \\
\hline & & & Lack of affection \\
\hline & & & Financial and economic problems \\
\hline & & & Continuous verbal and physical violence \\
\hline & & & Compulsory and unwanted marriage \\
\hline & & \multirow{5}{*}{$\begin{array}{l}\text { Underlying education and university } \\
\text { conditions }\end{array}$} & Distorted image of the university \\
\hline & & & Difficulty of training courses \\
\hline & & & Failure to fulfill expectations and ideals \\
\hline & & & The challenge of self-expression \\
\hline & & & Fear of double marginalization \\
\hline & & \multirow{5}{*}{$\begin{array}{l}\text { Underlying dormitory and } \\
\text { environmental conditions }\end{array}$} & Being sad for being away from family \\
\hline & & & Feel insecurity against others \\
\hline & & & $\begin{array}{l}\text { The challenge of independence and the difficulty of the tasks } \\
\text { assigned }\end{array}$ \\
\hline & & & Considering the dormitory as a closed framework \\
\hline & & & Repetitive cycle and boring routine \\
\hline & & \multirow{2}{*}{$\begin{array}{l}\text { Fear of the future and imagination of } \\
\text { a tomorrow full of darkness }\end{array}$} & Uncertain job future \\
\hline & & & Fear of double subaltern and being dominated again \\
\hline & & \multirow{3}{*}{$\begin{array}{l}\text { Cyberspace, experience of depression } \\
\text { and feelings of isolation }\end{array}$} & A decrease in the amount of verbal and emotional connections \\
\hline & & & Dissatisfaction with the unreal demonstrations of others \\
\hline & & & Trying to be similar with others \\
\hline & & \multirow{2}{*}{$\begin{array}{l}\text { Failed emotional attachment, } \\
\text { experience of depression and feelings } \\
\text { of grief }\end{array}$} & Joining an unhealthy friendship network \\
\hline & & & Emotional failure \\
\hline
\end{tabular}

what if I fail the courses. This issue caused a lot of pressure on me. Sometimes I become angry, get bored and I bother both myself and the others" (Nasrin, 19 years old).

On the other hand and given that many student studying in Zahedan had a rural origin or were "marginalized", they had less opportunity for "self-expression". In their own words, these conditions and contexts are much more "depressing". They face expectations that require a person to be in a situation that is far more difficult than their previous experiences. Samira described this situation as follows:

"I am a kid from the countryside; as many of the kids here. We have not experienced some things (situations), but sometimes [professors] we were asked something that we cannot do. For example, it's very difficult for us to come to our classroom and hold a conference. When the professors ask questions and we cannot answer, we are treated as if we do not understand anything. Well, we feel bad in the classroom. I swear to God that I will study hard, but I cannot show myself in the group. It is so difficult that you feel like this in front of your professor and the rest of the classmates" (Samira, 21 years old).
Here, perhaps, the fear of "humiliation" and receiving repressive feedbacks is the most important factor, due to which students have feelings of grief and mourning before anything happens. As if the marginalized individuals have not got accustomed to their situation and are satisfied with that; the fear is the only fear of a kind of "double marginalization". However, this is what happens and the university that was supposed to be a space for liberation, becomes a harder cage: an unfinished nightmare.

\subsection{Underlying Dormitory and Environmental Conditions}

The decision to travel from one's home to another city is not a simple decision and choice; put the individual's own apprehension, family's chaos, packing up the stuffs, packing up the luggage, saying goodbye to the family, passing the path and reaching the city where one is studying, one hand, going to the area which is considered as one's new place of life, which is called "dormitory", on the other hand. There should be an experience of dormitory life, in order to understand the meaning of sentences stated by someone who starts talking about his/her deep grief during his/her first entry into this new environment. Someone who says that here, shortly after the accommodation, you 
slowly realize that "you are your own father, mother, sister and brother! On this road, you are all alone"; and this (state of being all) will of course put the hardest and most difficult moments of your life, until now, in front of you.

"Before I went to college, I did not do all my own affairs alone, and I was not completely independent; that is, one is dependent on those who are living around him/her after all, but not here; you should also focus on cooking and eating alone too. You have to go to the classes and study, so I cannot do all these things alone; sometimes I start crying. On the other hand, before I came to university, I was an isolated person. I did not have much contact with anyone; I was a very shy person, but now I'm in such a place; I can hardly tolerate it. I study, but due to fear of talking in the classroom, I feel stressed, such that I cannot answer, that's why sometimes I become so upset that I did not want to study" (Maryam, 21 years old).

The talks show that the participants generally feel uncomfortable with being in the dormitory and living in a dormitory setting. The university setting, in general, and the dormitory setting, in particular, is considered as a "closed framework" where the student will soon be deeply involved in a "boring routine". Students stated that the duplication and repetitious state of everything has made their mind(s) tired and perceive this tired soul as an "experience of depression".

"Our daily routine is (going) to classrooms, selfservices, dormitories, (seeing) broken walls, dirty carpets; these! The environment is so bad that we don't wanna come here anymore. Here, they have placed us in a closed framework. We don't have any entertaining equipment, even a TV; I mean we have but the study room and TV room are in the same place where the kids (classmates) are studying. Only, we have Internet and there are cell phones everywhere which entertains everybody" (Ghazal, 20 years old).

However, "bad condition of the dormitories", as stated, is not limited to the aforementioned cases. It is not easy to live with individuals who have different social, cultural, and belief backgrounds and this is another annoying concern. Untidiness of the rooms, unorganized roommates and their special interests as well as their unreliable characters all lead to tensions and stresses that are beyond the threshold of patience and tolerance of the many residents; thus placing them in unstable mental conditions.

\subsection{The Fear of the Future and Imagining a Tomorrow Full of Darkness}

Iran is one of the countries with so-called young demographic structure; it was reported that about $50 \%$ of the country's population is less than 30 years old (19). On the other hand, a total of about of 70\% of Iran's population are at the employment age among whom the young people born in the 1980s and 1990s are searching for a job more than other age groups (20). The inappropriate conditions and economic infrastructure in the south east of Iran, which is the area of the present study, have led to the insignificant role of the private sector especially in this area and the lack of extensive entrepreneurship in practice. In such situation, the young job seekers of the area hope that the government and its sectors will take the necessary measures; the sectors that naturally do not have such capacity to meet the demands of such high number of applicants. The participants stated that they attended the university in order to continue their education and obtain higher degrees with the hope to be in a better position for employment opportunities. However, a very clear horizon has not been opened before their eyes, while looking at the situation of many of their close peers. Though, they are studying and promoting their level of education, but full of fear and the fear of the future and imagining a tomorrow full of darkness is always in their minds. Here, the point is to overcome thoughts occurring to the students' minds that are highly disappointing and causing fundamental and major challenges for them in terms of mental health. Considering the "double subaltern situation" of the girls of the region, this issue is more highly unpleasant for them.

"Why should we study so much? We study under a lot of pressure and unpleasant situation to obtain a degree and then graduate with no job! In our family, although my brothers, son of my aunt and son of my uncle (my dad's brother) have university degrees, they are still unemployed, then do you think there is any job out there for us as girls?" (Setareh, 22 years old).

Indeed, what is the future that is waiting for girls who choose to enter the university in order to make fundamental changes in their life hoping to overcome the traditional firm and hard structures governing their society and place of residence and undertake all the difficulties such as the dormitory life? Referring to the same theme and putting special emphasis on the presence of specific prejudices among the men of the region that are somehow due to the "ethnic and religious strictness", another student says:

"The thought of what will happen next, really bothers me. My fiance is now opposing my education saying I should not study. It is not customary for women to study here, except if I want to become a teacher there is no problem. I know when I graduate, I will have no alternative than to stay at home" (Narges, 20 years old).

\subsection{The Cyberspace, Experience of Depression and Feelings of Isolation}

The special emphasis put on the cyberspace was very interesting among all the notable points referred to in the participants' narratives, which however, prompts our reflection. According to the aforementioned conditions, the 
struggle and endeavor to get out of the atmosphere of frustration and despair, sometimes lead to no fruitful results due to these sub-factors. Students believed that their fundamental need in the dormitory setting is to have conversation and be beside individuals who help them overcome their feeling of loneliness; when this need is not met, then they are locked up in their own loneliness more than ever. The field observation and interviews show that "addiction to cyberspace" and the persistent presence of dormitory students in virtual social networks, have reduced the level of verbal and emotional communication among the so-called "roommates" to the minimum level; an issue that, according to participants' view, doubles "isolation and loneliness" and, subsequent, "depression.”

"Since I entered the dormitory, I see most of the kids going to the cyberspace; their world is just cyberspace! You can see kids in our room that are busy with their cell phones; sometimes they do not even notice the presence of each other. Such situation also affects you whether you like it or not, meaning if you do not want to enter such space, lack of any relationship between you and the others makes you spend most of your time in cyberspace. Well, this is not good, because the person feels more loneliness, especially when there is no one to chat with as they do; this even worsens the situation" (Aynaz, 20 years old).

As stated by the interviewee, in such context, other students will also be pushed towards using these networks willingly or unwillingly. At the meantime, those who feel uncomfortable in terms of mental health and mental comfort, discuss on new forms of mental anxiety, which are often due to their limited communication circle in social networks and their confrontation with unreal demonstrations of others; others who seem to feel better now and they spend their moments with less level of worries.

"I got obsessed and check my cell phone whenever I take it. I have to check the Telegram and Instagram groups frequently. Now, let's forget about telegram, whenever I open Instagram, I see one person has inserted a post; and see they have no problem; four other people come in and praise and applause her [...]. I'm conscience-stricken at wasting my time in this way; I do not have any time to do anything else; I make myself angry on one hand and I become stressed about doing my duties on the other" (Sima, 22 years old).

\subsection{Failed Emotional Attachment, Experience of Depression and Feelings of Grief}

According to the condition described earlier, researches are focused on finding "parapet"; a parapet which under its shadow one can forget upsetting problems even (if it is only) for short moments. The need for the presence of a person who can respond to this need has engaged most research participants and dormitory students in relationships that lead to a kind of "affective attachment"; often an emotional attachment to the opposite sex. Although this form of relationship is considered to be taboo in the studied socio-cultural context and includes restrictive prohibitions; according to students, it is the only way to get rid of the isolation.

"This framework, the long distance from the family and the dormitory atmosphere and the bad environment, make us to think of having relationship with the opposite sex. I saw many classmates who entered such relationships, but after some time, they broke up that led to a worse situation for them" (Ghazal, 20 years old).

Nevertheless, many of these relationships, as mentioned by the above participant, lead to "failure"; a failure which in reality or in other word "is the last blow" in the already collapsed mind of the people. The following narrative well illustrates this feeling of grief resulting from a failed emotional attachment.

"I had a really bad emotional failure; it has been one year since we are engaged, our marriage was definite, we were very intimate; I was emotionally attached to him; we were like husband and wife; such that we were constantly chatting and telephoning in the dormitory, until I knew that he also has relationships with several other girls apart from me [...]. My family opposed this from the very beginning and said he does not suit you, but I did not listen; I would say let me see the consequences with my own eyes! When I understood I was destroyed; I underwent a lot of psychological and mental pressure" (Kowsar, 21 years old).

\section{Discussion}

The findings of this research showed that many students experience a kind of depression while entering the university, which is also referred to by Furr et al. (2001) who conducted similar research on a number of students. The results of their study show that $53 \%$ of the subjects have experienced the depression phenomenon from the beginning of their presence in the university environment (21). In fact, the statements of a number of participants confirmed the fact that they were not essentially prepared for university and, in fact, dormitory life in advance, and had suddenly entered an environment they have not experienced before. In such circumstances and as Heidari and Rezaei interpreted, the feeling of insecurity towards any other person is the most important existential condition, which is understood by students at the time of their entering into the dormitory (22). The aforementioned feeling, which, however, leads to a degree of panic and anxiety in newcomer students, also leads to more depression especially for those who have been in the minority or marginalized position, a situation that seems to be experienced by all of the participants and indeed most dormitory students 
in the studied field. A number of previous studies have emphasized the significant relationship between depression feeling and mental health with the ethnic, religious, geographic, and economic backgrounds of students $(23,24)$.

Based on the results, it seems that being in a new situation does not only improve the previous situation, which, on the contrary, has created more unfortunate conditions; the discussion is about the conditions, the result which brings nothing but not a "sad life" for the participants. The sad life that is experienced by individuals is perceived as "depression", and is characterized with a number of major components such as "mental discomfort", "physical discomfort" and "social discomfort". The findings show that the experience of depression among students actually occurs through lack of mental balance and mental peace, painful physical harm, and disruption of social relationships and academic performance. Many other researchers have reported similar cases (25-27). Finally, the findings show that the aforementioned ailments are directing students to the spaces and relationships that although they have chosen to escape from the bad condition; they may have inverse consequences and involve them in a stressful cycle more than ever.

Therefore, it can be said that "situation in jeopardy" is perhaps the best concept or theme through which the "experience of depression" can be brought to an anthropological understanding. In fact, it seems that all participants are laden with anxiety, worry and apprehension caused by the problem threatening them. Some of the participants were in such a situation before entering the university and the dormitory environment, and many of them, upon arriving in the dormitory, found that their existential stability is lost in a declining process; in fact, the discussion is a kind of process, not an instantaneous event. In other words, the accumulation of stressors brings the person to the threshold suffering from, which means to surrender to all the difficulties in practice; a kind of inner collapse. These stressors initiated from a point and ended in the same point for participants of this study. In spaces illustrated earlier, all assumed that in most situations, considering the "superordinate" and "subaltern" states, are in the latter, as if they are the subalterns of a society who have a tendency to subject them in all fields. In a situation like this, depression is the product of difficult structures and depressed people seem to think that they cannot cope with these structures that reproduce themselves in different processes and affairs, ranging from socialization of individuals to gender stereotypes (28).

\subsection{Conclusions}

In spite of all the interpretations, the "agency" of some individuals cannot be ignored while making attempts to overcome the discussed exhausting conditions and what they called depression. A number of the participants, though few, by expressing that they are not willing to continue the described situation, have taken individual attempts to get out of it. On the one hand, organizational endeavors made by the university have been witnessed where students are studying in order to provide healthy recreational spaces such as gyms or sports halls and counseling centers that have an effective role in reducing students' mental health problems. However, given the persistence of bad mental feelings among a lot of participants and similar individuals, it seems that the Iranian academic spaces, especially in peripheral regions like the studied area, need to make additional efforts in order to pave way for the formation of wider support networks. On the other hand, we believed that it is important to consider rethinking about macro-socio-cultural and economic policies in Iran. Traditional thinking structures in society and social inequalities, on one hand and the existing mental image about the university, on the other hand, are pushing Iranian youths into a space, where they may soon face similar challenges that have been explained in this research.

\section{Footnotes}

Authors' Contribution: Contribution and role of authors in this research is equal.

Conflict of Interests: There are no conflict of interests.

Ethical Approval: In the text of the article -the methodology section- is explained. In addition, it should be noted that the present study was conducted on the basis of the credentials of the Research Deputy of the University of Sistan and Baluchestan. Credential number: 982/200/8087; date: May 24, 2018.

Funding/Support: This research has not received any financial support.

\section{References}

1. World Health Organization. Depression fact sheet; update February 2017. WHO; 2017.

2. Rawson HE, Bloomer K, Kendall A. Stress, anxiety, depression, and physical illness in college students. J Genet Psychol.1994;155(3):321-30. doi: 10.1080/00221325.1994.9914782. [PubMed: 7964658].

3. Dixon SK, Kurpius SER. Depression and college stress among university undergraduates: Do mattering and self-esteem make a difference? J Coll Student Dev. 2008;49(5):412-24. doi: 10.1353/csd.0.0024.

4. Bayram N, Bilgel N. The prevalence and socio-demographic correlations of depression, anxiety and stress among a group of university students. Soc Psychiatry Psychiatr Epidemiol. 2008;43(8):667-72. doi: 10.1007/s00127-008-0345-x. [PubMed: 18398558].

5. Andrews B, Wilding JM. The relation of depression and anxiety to lifestress and achievement in students. BrJPsychol. 2004;95(Pt 4):509-21. doi: 10.1348/0007126042369802. [PubMed: 15527535]. 
6. Ibrahim AK, Kelly SJ, Adams CE, Glazebrook C. A systematic review of studies of depression prevalence in university students. J Psychiatr Res. 2013;47(3):391-400. doi: 10.1016/j.jpsychires.2012.11.015. [PubMed: 23260171].

7. Naushad S, Farooqui W, Sharma S, Rani M, Singh R, Verma S. Study of proportion and determinants of depression among college students in Mangalore city. Niger Med J. 2014;55(2):156-60. doi: 10.4103/03001652.129657. [PubMed: 24791051]. [PubMed Central: PMC4003720].

8. Beiter R, Nash R, McCrady M, Rhoades D, Linscomb M, Clarahan M, et al. The prevalence and correlates of depression, anxiety, and stress in a sample of college students. J Affect Disord. 2015;173:90-6. doi: 10.1016/j.jad.2014.10.054. [PubMed: 25462401].

9. Brenneisen Mayer F, Souza Santos I, Silveira PS, Itaqui Lopes MH, de Souza AR, Campos EP, et al. Factors associated to depression and anxiety in medical students: A multicenter study. BMC Med Educ 2016;16(1):282. doi: 10.1186/s12909-016-0791-1. [PubMed: 27784316] [PubMed Central: PMC5080800].

10. Nelson JM, Liebel SW. Anxiety and depression among college students with attention-deficit/hyperactivity disorder (ADHD): Cross-informant, sex, and subtype differences. J Am Coll Health. 2018;66(2):123-32. doi: 10.1080/07448481.2017.1382499. [PubMed: 28937938].

11. Rahiminia H, Rahiminia E, Sharifirad G. Assessment of physical, psychological, social, and environmental health domains of quality of life in female students living in dormitories of Qom University of Medical Sciences. Int Arch Health Sci. 2017;4(4):93. doi: 10.4103/iahs.iahs_18_17.

12. Kim H, Kim S. Psychological and emotional stress among the students living in dormitory: A comparison between normal and depressive students. J Sleep Disord Ther. 2015;4(3):1-6. doi: 10.4172/21670277.1000201.

13. The Management and Planning Organization of Sistan and Baluchestan Province. [Selection of economic, social and sultural indexes and indicators]. 2016. Persian.

14. Creswell JW. Research design: Qualitative, quantative and mixed methods approaches. London: Sage; 2011

15. Moustakas C. Phenomenological research methods. Thousand Oaks, CA: Sage; 1994. doi: 10.4135/9781412995658.
16. Braun V, Clarke V. Using thematic analysis in psychology. Qual Res Psychol. 2006;3(2):77-101. doi: 10.1191/1478088706qp063oa.

17. Denzin NK. The research act. 3rd ed. Englewood Cliffs, NJ: Prentice Hall; 1989.

18. Creswell JW. Qualitative inquiry and research design: Choosing among five approaches. Thousand Oaks, CA: Sage; 2006.

19. Zahedian A. 50 percent of the [Iran] population are under 30 years of age; lecture at the congress of health sciences, reproductive and pediatric. 2017. Available from: https://www.amar.org.ir.

20. Sayari A. 11 million of iranian young people are in the marriage age and 70 percent of the country's population are in the working age. 2018. Available from: https://www.yjc.ir/.

21. Furr SR, Westefeld JS, McConnell GN, Jenkins JM. Suicide and depression among college students: A decade later. Prof Psychol Res Pract. 2001;32(1):97-100. doi: 10.1037/0735-7028.32.1.97.

22. Heidari H, Rezaei A. [Sociological analysis of professional identity of the students, case study: Students of University of Mazandaran].JIran Cult Res. 2012;5(2):1-29. Persian. doi:10.7508/ijcr.2012.18.001.

23. Hamdan-Mansour AM, Halabi JO, Dawani HA. Depression, hostility, and substance use among university students in Jordan. Ment Health Subst Use. 2009;2(1):52-63. doi: 10.1080/17523280802593301.

24. Eisenberg D, Hunt J, Speer N. Mental health in American colleges and universities: Variation across student subgroups and across campuses. J Nerv Ment Dis. 2013;201(1):60-7. doi: 10.1097/NMD.ob013e31827ab077. [PubMed: 23274298].

25. Heiligenstein E, Guenther G, Hsu K, Herman K. Depression and academic impairment in college students.JAm Coll Health.1996;45(2):5964. doi: 10.1080/07448481.1996.9936863. [PubMed: 8908879].

26. Hysenbegasi A, Hass SL, Rowland CR. The impact of depression on the academic productivity of university students.J Ment Health Policy Econ. 2005;8(3):145-51. [PubMed:16278502].

27. Herman S, Archambeau OG, Deliramich AN, Kim BS, Chiu PH, Frueh BC. Depressive symptoms and mental health treatment in an ethnoracially diverse college student sample. J Am Coll Health. 2011;59(8):715-20. doi: 10.1080/07448481.2010.529625. [PubMed: 21950252]. [PubMed Central: PMC3210726].

28. Brown GW, Harris T. Social origins of depression: A study of psychiatric disorder in women. London: Tavistock Publications; 1978. 